\title{
Effects of stanozolol on normal and IL-1 $\beta$-stimulated equine chondrocytes in vitro
}

\author{
Mariana Castro Martins ${ }^{1^{*}} \mathbb{D}$, Mandy J. Peffers ${ }^{2}$, Katie Lee ${ }^{2}$ and Luis M. Rubio-Martinez ${ }^{1}$
}

\begin{abstract}
Background: Intra-articular administration of stanozolol has shown promising results by improving the clinical management of lameness associated with naturally-occurring osteoarthritis (OA) in horses, and by decreasing osteophyte formation and subchondral bone reaction in sheep following surgically induced OA. However, there is limited evidence on the anti-inflammatory and modulatory properties of stanozolol on articular tissues. The objective of the current study was to evaluate the effects of stanozolol on chondrocyte viability and gene expression in normal equine chondrocytes and an inflammatory in vitro system of OA (interleukin-1 $\beta$ (IL-1 $\beta$ ) treated chondrocytes).

Results: Chondrocytes from normal metacarpophalangeal joints of skeletally mature horses were exposed to four treatment groups: (1) media only (2) media+IL-1 $\beta$ (3) media+IL-1 $\beta$ + stanozolol (4) media+stanozolol. Following exposure, chondrocyte viability and the expression of catabolic, anabolic and structural genes were determined. General linear models with Dunnet's comparisons with Bonferroni's adjustment were performed. Cell viability was similar in all groups. Stanozolol treatment reduced gene expression of MMP-13, MMP-1, IL-6 and COX-2 in both normal and IL-1 $\beta$ treated chondrocytes. Stanozolol treatment reduced ADAMTS4 gene expression in normal chondrocytes. Stanozolol reduced the expression of COL2A1.

Conclusions: The current study demonstrates stanozolol has chondroprotective effects through downregulation of genes for pro-inflammatory/catabolic cytokines and enzymes associated with OA. However, there is no evidence of increased cartilage stimulation through upregulation of the anabolic and structural genes tested.
\end{abstract}

Keywords: Osteoarthritis, Stanozolol, Chondrocyte, Equine, Gene expression, In vitro

\section{Background}

Osteoarthritis (OA) is caused by a combination of biomechanical and biochemical changes in the joint that include synovium and subchondral bone abnormalities, ultimately resulting in cartilage degeneration [1]. In the past decade, major advances have been made in molecular biology and OA research in both human and veterinary medicine. Equine models have been used extensively providing invaluable insights into the molecular pathogenesis during disease establishment and in response to treatment $[2,3]$.

\footnotetext{
* Correspondence: mcm@liverpool.ac.uk

${ }^{1}$ Department of Equine Clinical Studies, Institute of Veterinary Science, University of Liverpool, Leahurst Campus, Chester High Road, Neston CH64 7TE, UK

Full list of author information is available at the end of the article
}

One of the main goals in the treatment of OA is to inhibit further progression of cartilage degeneration and to restore a functional synovial environment with the potential to promote cartilage repair. Cartilage repair is mediated by the balance between chondrocyte gene expression of catabolic and anabolic genes [4, 5]. The most important mediator of cartilage degeneration is interleukin-1 (IL-1) [5, 6] and it has been reported that low innate production of IL-1 $\beta$ and IL- 6 is associated with the absence of OA in old age [7]. IL-1 enhances the expression of pro-inflammatory mediators including matrix metalloproteinases (MMP-3 and -13), inflammatory cytokines (IL-6), a disintegrin and metalloproteinase with thrombospondin motifs (ADAMTS-4 and -5), cyclooxygenase 2 (COX-2), prostaglandin E2 (PGE2) and free radicals [1]. Cartilage repair is mediated by anabolic 
growth factors including the transforming growth factor $\beta$ (TGF- $\beta$ ), insulin-like growth factor 1 (IGF-1), bone morphogenetic proteins (BMPs) and fibroblast growth factors (FGF) [8]. The IGF-1, TGF- $\beta$ and BMPs act in part by induction of the transcription factor SOX-9, a key regulator of mesenchymal chondrogenesis during embryologic development $[9,10]$. No therapy is currently available to prevent the onset or progression of $\mathrm{OA}$, and latest research has focused on disease-modifying drugs with the capacity not only to counteract the effects of pro-inflammatory cytokines but also to promote articular cartilage repair.

Anabolic-androgenic steroids (AAS) are synthetic derivatives of testosterone and were first introduced in the early 1930s. Since then, an attempt has been made to minimize the androgenic side effects by increasing their anabolic: androgenic ratio. Stanozolol has one of the highest anabolic: androgenic ratios, suggesting it has anabolic activity with minimal androgenic side effects [11]. Stanozolol has a wide range of applications in human medicine and has been used to treat rheumatoid arthritis [12, 13], hereditary angioedema [14], idiopathic osteonecrosis [15], postmenopausal osteoporosis [16, 17], muscle wastage and age-related sarcopenia [11], amongst others [18]. The main claims for stanozolol's therapeutic effects are based on its anabolic activity on the musculoskeletal system and its potential to influence lean body mass, tissue repair, fibrinolysis, collagen synthesis and bone metabolism [11]. To our knowledge there are no human studies evaluating the effects of AAS on articular cartilage and there are no reports on the intra-articular use of stanozolol in human patients.

Intra-articular administration of stanozolol has recently been postulated as a treatment for OA. Studies investigating the clinical effects of the intra-articular use of stanozolol in horses have shown promising results in the ability of this drug to effectively manage lameness associated with OA and have suggested that stanozolol has the potential to stimulate cartilage repair $[19,20]$. There is also anecdotal evidence of positive results obtained in equine clinical practice, including cases refractory to intra-articular glucocorticoids [21] and in the management of subchondral bone pain [22]. Furthermore, stanozolol has been used in an experimental animal model (sheep meniscectomy), demonstrating decreased osteophyte formation, subchondral bone reaction and synovial fibrosis, and articular cartilage regeneration [23]. However, there is limited evidence of the antiinflammatory properties of stanozolol and how it affects articular chondrocytes in vitro. Previous data suggests that it reduces chondrocyte apoptosis by decreasing the production of nitric oxide in equine chondrocytes [24], enhances collagen synthesis though the upregulation of TGF- $\beta$ in adult human dermal fibroblasts [25] and enhances the proliferation of cultured growth plate chondrocytes from pubertal female rats treated with GnRHa [26].
The objective of the current study is to evaluate the effect of stanozolol on chondrocyte viability and gene expression in normal chondrocytes and an in vitro inflammatory system of OA. We hypothesise that stanozolol will not have an effect on chondrocyte viability; will have a chondroprotective effect by reducing the expression of pro-inflammatory/catabolic genes (MMP-13, MMP-1, IL-6, ADAMTS4 and COX-2) in both normal and IL-1 $\beta$ treated chondrocytes; and will have an anabolic effect by increasing the expression of SOX9, COL2A1 and aggrecan in both normal and IL-1 $\beta$ treated chondrocytes.

\section{Methods}

\section{Sample collection}

Articular cartilage was aseptically harvested from the entire articular surface of macroscopically normal metacarpophalangeal joints of seven skeletally mature horses euthanized for reasons unrelated to this study, ages ranging from five to eleven years (mean $7.7+/$ - SD 2.1) Samples were collected from an abattoir as a by-product of the agricultural industry and processed within $12 \mathrm{~h}$ of euthanasia. The Animals (Scientific Procedures) Act 1986, Schedule 2, does not define collection from these sources as scientific procedures and ethical approval was therefore not required.

\section{Tissue culture and cell viability}

The chondrocytes were isolated as previously described [27] and the cell viability was determined by trypan blue exclusion test [28] for each horse. The chondrocytes were then plated as monolayers in Dulbecco's modified eagles medium (DMEM) (Sigma-Aldrich, Dorset, UK), supplemented with $10 \%$ foetal calf serum (FCS), 100 units $/ \mathrm{ml}$ penicillin, $100 \mathrm{mg} / \mathrm{ml}$ streptomycin (all from Invitrogen, Paisley, UK) and $500 \mathrm{ng} / \mathrm{ml}$ amphotericin B (BioWhittaker, Lonza, USA), at a concentration of 100,000 live cells $/ \mathrm{cm}^{2}$ (total of 16 wells of a 24-well plate used per horse). The chondrocytes were incubated in a $5 \% \mathrm{CO}_{2}$ humidified atmosphere at $37{ }^{\circ} \mathrm{C}$ for $48 \mathrm{~h}$. The medium was changed and replaced with serum-free DMEM $24 \mathrm{~h}$ prior to exposure. Each horse was exposed to 4 different treatment groups (4 wells per group): (1) media only (negative control) (2) media + IL-1 $\beta$ (Recombinant Equine IL-1 $\beta$, R\&D Systems, Abingdon, UK) $(10 \mathrm{ng} / \mathrm{ml}$ ) (positive control) (3) media + IL-1 $\beta(10 \mathrm{ng} / \mathrm{ml})+$ stanozolol (Sungate, ACME, Cavriago, Italy) $(0.4 \mathrm{mg} / \mathrm{ml}) 4)$ media + stanozolol $(0.4 \mathrm{mg} / \mathrm{ml})$. The stanozolol concentration was extrapolated by using the clinically recommended dose of $5 \mathrm{mg}$ per joint [20] and assuming the volume of a non-distended metacarpalphalangeal joint to be $12.5 \mathrm{ml}$ [29]. After $24 \mathrm{~h}$ in culture conditions, cell viability was performed on one well per group. 


\section{Real-time PCR}

Total RNA was isolated separately from 3 wells per group using $0.5 \mathrm{ml}$ of Tri Reagent (Sigma-Aldrich, Dorset, UK) per well and stored at $-80{ }^{\circ} \mathrm{C}$ for later analysis. The RNA isolated from each well was processed individually and was purified by the acid guanidinium thiocyanate-phenol-chloroform extraction technique as previously described [30]. Total RNA concentrations and purity were determined spectrophotometrically (NanoDrop $^{\mathrm{TM}} 1000$ Spectrophotometer, Thermo Fisher Scientific, Waltham, US) and all the samples used presented a ratio of absorbance at $260 \mathrm{~nm}$ and $280 \mathrm{~nm}$ $\left(\mathrm{A}_{260} / \mathrm{A}_{280}\right)$ between 1.8 and 2.0. cDNA was synthetized from $500 \mathrm{ng}$ of RNA in a $29 \mu \mathrm{L}$ reaction using Moloney Murine Leukemia Virus Reverse Transcriptase (M-MLV RT) and random hexamer oligonucleotides (both Promega, Southampton, UK). cDNA samples were individually diluted to a final concentration of $5 \mathrm{ng} / \mu \mathrm{L}$ and $5 \mu \mathrm{L}$ aliquots of cDNA were amplified by reverse transcription polymerase chain reaction (RT-PCR) (ABI PRISM ${ }^{\circ}$ 7500 Sequence Detection System, Applied Biosystems, Warrington, UK) in a $20 \mu \mathrm{L}$ reaction volume using a SYBR Green PCR mastermix (Applied Biosystems, Warrington, UK). Glyceraldehyde 3-phosphate dehydrogenase $(\mathrm{GAPDH})$ was used as the housekeeping gene and the relative expression of catabolic, anabolic and structural genes was analysed using the $2_{\mathrm{T}}^{-\Delta \Delta \mathrm{C}}$ method [31]. The fitness of GAPDH as a valid normalisation factor has been previously identified by us $[32,33]$. All primers used were designed by Applied Biosystems Assays-byDesign and have been previously validated by our group. Primers for equine IL-6 and COX-2 had the following sequences: IL-6 Forward: CTG-CTC-CTG-GTG-ATG-G CT-AC, Reverse: CCG-AGG-ATG-TGT-ACT-TAA-T GT-GCT-G; COX-2 Forward: CAG-CAT-AAA-CTG-C GC-CTT-TTC, Reverse: AGG-CGG-GTA-GAT-CAT-T TC-CA. The primer sequences for GAPDH, SOX9, COL2A1, aggrecan, MMP-13 and -1 , and ADAMTS4 have been previously reported [32, 34].

\section{Statistical analysis}

Statistical analysis was performed using SPSS (IBM, Portsmouth, UK). Normality of the data was analysed using a Shapiro-Wilk test, and non-parametric data was $\mathrm{LOG}_{10}$ transformed prior to analysis. A general linear model was used for all analyses with Dunnet's comparisons against the control group and pairwise comparisons with Bonferroni's adjustment. Statistical significance was defined as $P<0.05$.

\section{Results}

Stanozolol does not affect chondrocyte viability

There were no significant differences in cell viability between the different treatment groups.

\section{Stanozolol reduces catabolic gene expression}

There was a statistically significant increase in the expression of MMP-13, MMP-1, IL-6, ADAMTS4 and COX-2 mRNA expression in chondrocytes treated with IL-1 $\beta$ only (group 2- positive control) compared to media only (group 1 - negative control) $(P<0.001)$. Conversely, chondrocytes exposed to stanozolol only (group 4) had a significantly decreased expression of all the above catabolic genes compared to the negative control (group 1) $(P<0.001)$ (Fig. 1).

When comparing both groups with IL- $1 \beta$ treated chondrocytes, there was a significant downregulation of MMP$13(P<0.001)$, MMP-1 $(P<0.03)$, IL-6 $(P<0.001)$ and COX-2 $(\mathrm{P}<0.001)$ expression in chondrocytes exposed to IL-1 $\beta$ and stanozolol (group 3 ) compared to chondrocytes exposed to IL-1 $\beta$ alone (group 2). ADAMTS4 gene expression was not significantly supressed in chondrocytes exposed to IL-1 $\beta$ and stanozolol (group 3) compared to chondrocytes exposed to IL-1 $\beta$ only (group 2) (Fig. 1).

\section{Stanazolol reduces COL2A1 gene expression}

There was no statistically significant difference in SOX9 gene expression between treatment groups. COL2A1 gene expression was significantly supressed in both groups treated with stanozolol (groups 3 and 4) compared to both groups not treated with stanozolol (groups 1 and 2). Aggrecan gene expression was significantly supressed in both groups treated with IL-1 $\beta$ (groups 2 and 3) compared to both groups not treated with IL-1 $\beta$ (groups 1 and 4). No statistically significant difference was seen on COL2A1 gene expression between groups 1 and 2 or 3 and 4 , or on aggrecan expression between groups 1 and 4 or 2 and 3 (Fig. 2).

\section{Discussion}

In OA the balance between anabolic and catabolic activities is compromised and cartilage degeneration prevails over the capacity of repair. In the present study, treatment with stanozolol was investigated in both normal and IL-1 $\beta$ stimulated chondrocytes. In accordance with previous reports [35-37] exposure to IL-1 $\beta$ induced a catabolic response on equine articular chondrocytes and increased the gene expression of MMP-13, MMP-1, IL-6, ADAMTS4 and COX-2. Addition of stanozolol to IL-1 $\beta$ stimulated chondrocytes counteracted the catabolic effects of IL-1 $\beta$ and downregulated the expression of MMP-13, MMP-1, IL-6, and COX-2. Similarly, corticosteroids have been demonstrated to inhibit MMP transcription [38-42] and downregulate the expression of COX-2 [40-42] in cytokine-treated chondrocytes. In the present study, stanozolol supressed ADAMTS4 gene expression in normal chondrocytes compared to control but did not counteract the upregulation induced by IL$1 \beta$. This is in contrast with observations in corticosteroids studies $[39,40]$. 

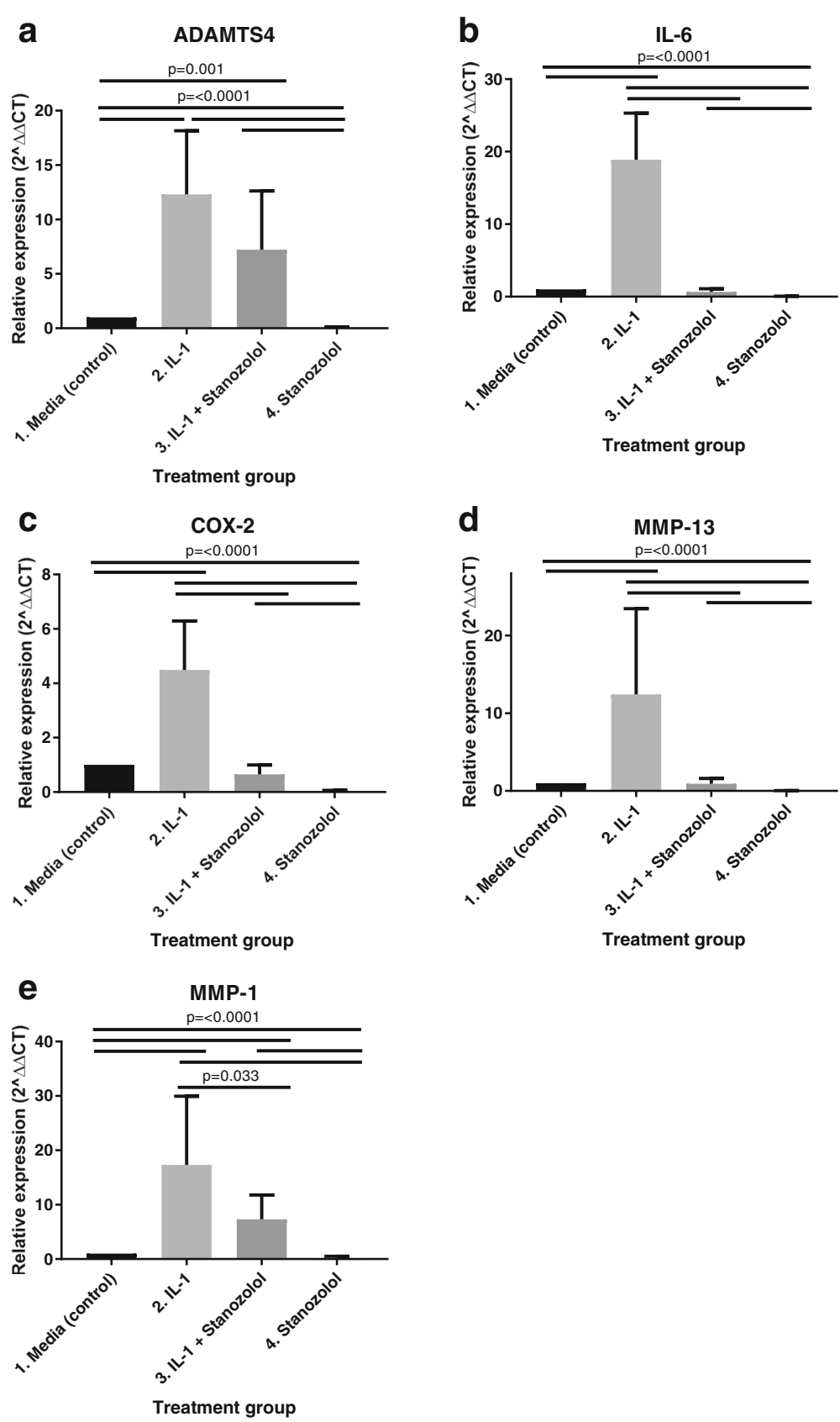

Fig. 1 Effects of stanozolol on (a) ADAMTS4, (b) IL-6, (c) COX-2, (d) MMP-13 and (e) MMP-1 gene expression in normal and IL-13-treated equine articular chondrocytes. Real-time-PCR analysis of the above genes mRNA in monolayer cultures exposed to media, IL-1 $\beta$, IL-1 $\beta+$ stanozolol and stanozolol. GAPDH was used as the housekeeping gene and data are represented as relative expression using the $2_{T}^{-\Delta \Delta C}$ method. Data were evaluated using a general linear model with Dunnet's comparisons against the control group and pairwise comparisons with Bonferroni's adjustment $(n=7$, three technical replicates per treatment group)

Further analysis of our results showed that when normal chondrocytes were treated with stanozolol there was a significant decrease in the expression of all the catabolic genes tested (MMP-13, MMP-1, IL-6, ADAMTS4 and COX-2) compared to control. Again, similar results have been obtained in in vitro models studying the effects of corticosteroids on articular cartilage [38, 39]. Knych et al.
[43] recently evaluated changes in synovial fluid gene expression following in vivo administration of triamcinolone in healthy horses undergoing a standardized exercise programme. In this study they found no significant differences in COX-2 and MMP-3 gene expression between baseline and the triamcinolone treatment group. These results suggest a protective and stronger anti-inflammatory 


\section{a}

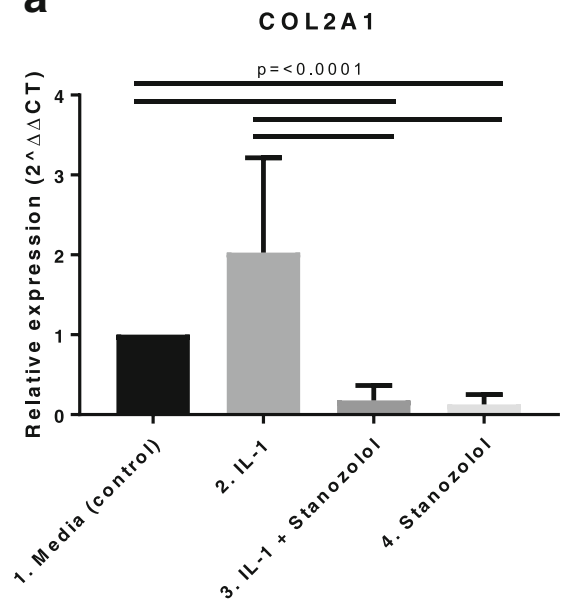

Treatment group

C

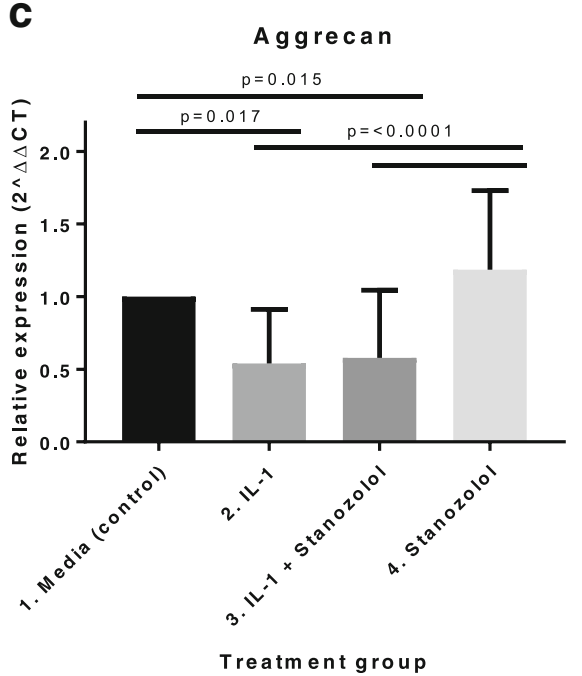

b

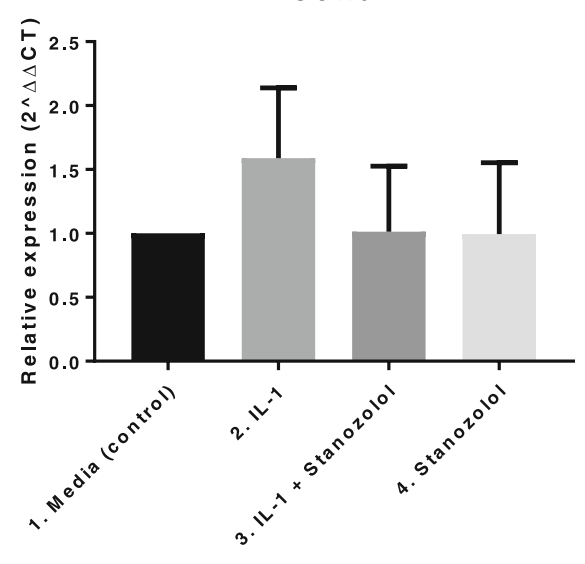

Treatment group

Fig. 2 Effect of stanozolol on (a) COL2A1, (b) SOX-9 and (c) aggrecan gene expression in normal and IL-1 $\beta$-treated equine articular chondrocytes. Real-time-PCR analysis of the above genes mRNA in monolayer cultures exposed to media, IL-1 $\beta$, IL-1 $\beta+$ stanozolol and stanozolol. GAPDH was used as the housekeeping gene and data are represented as relative expression using the $2_{T}^{-\Delta \Delta C}$ method. Data were evaluated using a general linear model with Dunnet's comparisons against the control group and pairwise comparisons with Bonferroni's adjustment $(n=7$, three technical replicates per treatment group)

response after intra-articular administration of stanozolol compared to triamcinolone; however, different experimental models limit direct comparisons between studies.

Contrary to our hypothesis, stanozolol did not enhance the expression of SOX-9, COL2A1 or aggrecan. The pathway through which anabolic growth factors promote upregulation of chondrocyte specific genes remains largely unclear. The transcription factor SOX9 has elicited much interest as it is co-expressed with type II collagen in mouse fetal chondrocytes and is thought to be involved in chondrocyte differentiation and cartilage formation during development [44]. SOX9 has been shown to mediate the expression of many genes encoding cartilage extracellular matrix proteins, including COL2A1 and aggrecan [9, 45, 46]. Kolettas et al. [9] investigated the effects of IGF-1 and IL-1 on chondrocyte survival and phenotype and reported an antagonist effect. IL-1 supressed the expression of chondrocyte-specific genes (collagen types II and IX, aggrecan, biglycan and link protein) and downregulated SOX-9; and IGF-1 upregulated SOX-9, relieved the IL-1 induced inhibition of chondrocyte-specific genes and enhanced chondrocyte survival. The authors therefore suggested that IGF-1 and IL-1 modulate chondrocyte survival and differentiation through changes in SOX-9 gene expression. Further studies have challenged this concept and showed a negative correlation between COL2A1 and SOX9 gene expression. In human adult articular chondrocytes, IL-1 had no significant influence on SOX9 mRNA expression whereas COL2A1 was significantly down- 
regulated. The same experiment also demonstrated that IGF-I up-regulated COL2A1 expression, but not SOX9 [47]. In our study, treatment with IL-1 and stanozolol, alone or in combination, did not alter SOX-9 gene expression in comparison to control. IL-1 did not downregulate SOX-9 as previously reported, had no effect on COL2A1 and downregulated aggrecan expression. Furthermore, treatment with stanozolol supressed COL2A1 without affecting SOX-9 gene expression. Our results suggest that COL2A1 and aggrecan gene expression are not correlated with the expression of SOX9 in equine articular chondrocytes and that treatment with stanozolol does not elicit an anabolic response through the upregulation of SOX-9, COL2A1 or aggrecan.

Both COL2A1 and aggrecan are important structural genes essential for cartilage integrity and formation. Stanozolol has been shown to increase collagen synthesis in cultures of human dermal fibroblasts [25]. The decrease in COL2A1 levels, which we have observed when chondrocytes were treated with stanozolol, goes against what has been reported in human dermal fibroblasts, and is similar to that reported by Knych et al. [43] in synovial fluid and Richardson and Dodge [38] in articular chondrocytes following treatment with corticosteroids. In the present study, aggrecan expression was downregulated by IL-1 $\beta$ and treatment with stanozolol did not ameliorate the IL-1 inhibition of aggrecan, which is also in accordance with what has been reported with corticosteroids [38]. Furthermore, the downregulation of COL2A1 induced by stanozolol in this study warrants careful consideration of its intra-articular use as it may suggest deleterious effects on cartilage. A limitation of our study is the use of a short-term in vitro system and different results may have been obtained with longer exposure times or with repeat exposures mimicking what has been described in clinical trials. Additionally, this study used chondrocytes and not cartilage explants. However, we used freshly isolated chondrocytes plated at high density in order to reduce dedifferentiation of chondrocytes in cell culture which can results in an altered phenotype. Future studies using cartilage explants are needed.

The similarities between the anti-catabolic effects of stanozolol and corticosteroids might be associated with the previously reported affinity of AAS for the glucocorticoid receptors [48]. Alternative pathways through which AAS might be able to exert an anabolic effect on articular tissues merit further investigation; and a plausible explanation for the lack of anabolic activity in our in vitro system might be related to a single and short-lived exposure time. Further studies investigating the systemic effects of a low intra-articular dose of stanozolol and its local effects on articular tissues with naturally-occurring $\mathrm{OA}$ are warranted. The use of AAS is banned by the main organizations overseeing drug regulation in sport, therefore its use should only be considered in noncompeting individuals.

\section{Conclusions}

Stanozolol has been described as having disease-modifying activity by attenuating the degenerative response in osteoarthritic cartilage in in vivo studies. The results of our in vitro study support the hypothesis that stanozolol has an anti-inflammatory effect and is effective at inhibiting the production of pro-inflammatory mediators in both normal and IL-1 treated chondrocytes. However, in our in vitro system there is no evidence of stanozolol having an anabolic effect through upregulation of SOX-9, COL2A1 and aggrecan gene expression.

\begin{abstract}
Abbreviations
AAS: Anabolic-androgenic steroids; ADAMTS: Disintegrin and metalloproteinase with thrombospondin motifs; BMPs: Bone morphogenetic proteins; cDNA: Complimentary deoxyribonucleic acid; $\mathrm{CO}_{2}$ : Carbon dioxide; COL2A1: Collagen type 2 alpha 1; COX-2: Cyclooxygenase-2;

DMEM: Dulbecco's modified eagles medium; FCS: Foetal calf serum; FGF: Fibroblast growth factor; GAPDH: Glyceraldehyde 3-phosphate dehydrogenase; GnRHa: Gonadotropin-releasing hormone agonist; IGF-1: Insulin-like growth factor 1; IL-1 $\beta$ : Interleukin-1 $\beta$; IL-6: Interleukin 6; M-MLV RT: Moloney Murine Leukemia Virus Reverse Transcriptase; MMP: Matrix metalloproteinase; mRNA: Messenger ribonucleic acid; OA: Osteoarthritis; PGE2: Prostaglandin E2; RT-PCR: Reverse transcription polymerase chain reaction; SOX-

9: Transcripton gactor SOX-9; TGF- $\beta$ : Transforming growth factor $\beta$
\end{abstract}

\section{Acknowledgements}

The authors would like to thank Maria M. Torres for her assistance in the acquisition of data.

\section{Funding}

This study was funded by the Institute of Veterinary Science, University of Liverpool (VET039-VSRP). Mandy Peffers is funded through a Wellcome Trust Intermediate Clinical Fellowship (107471/Z/15/Z)

\section{Availability of data and materials}

Raw data (Excel file) is available from the corresponding author upon request.

\section{Authors' contributions}

MCM, LRM and MJP were involved in the conception, design of the study and experiments, and the analysis and interpretation of data. MCM was involved in organizing this research, the acquisition of data and drafting the manuscript. KL was involved in the statistical analysis and interpretation of data. All authors read and approved the final manuscript.

\section{Ethics approval and consent to participate \\ Tissue samples from deceased horses euthanized for reasons unrelated to this study were collected from an abattoir as a by-product of the agricultural industry. The Animals (Scientific Procedures) Act 1986, Schedule 2, does not define collection from these sources as scientific procedures and ethical approval was therefore not required.}

Consent for publication

Not applicable.

Competing interests

The authors declare that they have no competing interests.

\section{Publisher's Note}

Springer Nature remains neutral with regard to jurisdictional claims in published maps and institutional affiliations. 


\section{Author details}

Department of Equine Clinical Studies, Institute of Veterinary Science, University of Liverpool, Leahurst Campus, Chester High Road, Neston CH64 7TE, UK. ${ }^{2}$ Department of Musculoskeletal Biology, Institute of Ageing and Chronic Disease, University of Liverpool, Liverpool, UK.

Received: 23 September 2017 Accepted: 14 March 2018

Published online: 20 March 2018

\section{References}

1. Mcllwraith CW. Traumatic arthritis and posttraumatic osteoarthritis in the horse. In: CW MI, Frisbie DD, Kawcak C, van Weeren R, editors. Joint disease in the horse. 2nd ed. Missouri: Elsevier; 2016. p. 33-48.

2. Little CB, Smith MM. Animal models of osteoarthritis. Cur Rheumatol Rev. 2008:4(3):175-82

3. Mcllwraith CW, Frisbie DD, Kawcak CE. The horse as a model of naturally occurring osteoarthritis. Bone Joint Res. 2012;1(11):297-309.

4. Goldring MB, Otero M, Tsuchimochi $K$, et al. Defining the roles of inflammatory and anabolic cytokines in cartilage metabolism. Ann Rheum Dis. 2008;67(Suppl 3):iii75-82.

5. Mueller MB, Tuan RS. Anabolic/catabolic balance in pathogenesis of osteoarthritis: identifying molecular targets. PM\&R. 2011;3(6):S3-11.

6. Blom AB, Van Der Kraan PM, Van Den Berg WB. Cytokine targeting in osteoarthritis. Curr Drug Targets. 2007;8(2):283-92.

7. Goekoop RJ, Kloppenburg M, Kroon HM, et al. Low innate production of interleukin-1 $\beta$ and interleukin- 6 is associated with the absence of osteoarthritis in old age. Osteoarthr Cartil. 2010;18(7):942-7.

8. Fortier LA, Barker JU, Strauss EJ, et al. The role of growth factors in cartilage repair. Clin Orthop Relat Res. 2011;469(10):2706-15.

9. Kolettas E, Muir HI, Barrett JC, Hardingham TE. Chondrocyte phenotype and cell survival are regulated by culture conditions and by specific cytokines through the expression of sox-9 transcription factor. Rheumatology. 2001; 40(10):1146-56.

10. Wagner T, Wirth J, Meyer J, et al. Autosomal sex reversal and campomelic dysplasia are caused by mutations in and around the SRY-related gene SOX9. Cell. 1994;79(6):1111-20.

11. Evans NA. Current concepts in anabolic-androgenic steroids. Am J Sports Med. 2004;32(2):534-42.

12. Belch JJ, Madhok R, McArdle B, et al. The effect of increasing fibrinolysis in patients with rheumatoid arthritis: a double blind study of stanozolol. Q J Med. 1986;58(1):19-27.

13. Pullar T. Disease modifying drugs for rheumatoid arthritis: yesterday's treatment today or today's treatment tomorrow? Br J Clin Pharmacol. 1990;30(4):501-10.

14. Sloane DE, Lee CW, Sheffer AL. Hereditary angioedema: safety of long-term stanozolol therapy. J Allergy Clin Immunol. 2007:120(3):654-8.

15. Glueck CJ, Freiberg R, Glueck HI, et al. Idiopathic osteonecrosis, hypofibrinolysis, high plasminogen activator inhibitor, high lipoprotein (a), and therapy with Stanozolol. Am J Hematol. 1995;48(4):213-20.

16. Chesnut $\mathrm{CH}$, Ivey JL, Gruber HE, et al. Stanozolol in postmenopausal osteoporosis: therapeutic efficacy and possible mechanisms of action. Metabolism. 1983;32(6):571-80.

17. El-Ganzuri MA, Ahmed RR, Bastawy EM. Osteoporosis and its treatments. Int. J Adv Res. 2015;3(9):303-18.

18. Helfman T, Falanga V. Stanozolol as a novel therapeutic agent in dermatology. J Am Acad Dermatol. 1995;33(2):254-8.

19. Spadari A, Rinnovati R, Babbini S, Romagnoli N. Clinical evaluation of intraarticular administration of stanozolol to manage lameness associated with acute and chronic osteoarthritis in horses. J Equine Vet Sci. 2015;35(2):105-10

20. Rinnovati R, Romagnoli N, Spadari A. Dose-finding study for intraarticular treatment with Stanozolol in horses. J Equine Vet Sci. 2015:35(10):860-4

21. Ramzan P, Somerville G, Shepherd M, et al. Preliminary clinical impressions on the use of stanozolol as a novel intra-articular therapy for athletic horses: 60 cases (abstract). In: Abstracts European veterinary conference Voorjaarsdagen; 2012. file:///C:/Users/mcm/Downloads/CH08-RamzanPreliminaryClinical\%20(1).pdf. Accessed 4 Apr 2012

22. Bladon B. Managing subchondral bone pain in thoroughbreds. Birmingham: Beva Congress Proceedings; 2012. p. 170.

23. Spadari A, Romagnoli N, Predieri PG, et al. Effects of intraarticular treatment with stanozolol on synovial membrane and cartilage in an ovine model of osteoarthritis. Res Vet Sci. 2013;94(3):379-87.
24. Saleri R, Dondi M, Bianchi E, et al. Stanozolol inhibits nitric oxide production by horse chondrocyte cell cultures (abstract). Abstracts from the workshop: Frontiers of skeletal biology. Bone. 2004;34:S38-9.

25. Falanga $V$, Greenberg AS, Zhou $L$, et al. Stimulation of collagen synthesis by the anabolic steroid stanozolol. J Invest Dermatol. 1998;111(6):1193-7.

26. Shun-ye ZH, Hua-mei MA, Yan-hong LI, et al. Effects of Stanozolol on proliferation and differentiation of cultured growth plate chondrocytes from pubertal female rat treated with GnRHa in vitro. J Sun Yat-Sen Univ (Med Sci). 2009:4:018.

27. Tew SR, Murdoch AD, Rauchenberg RP, Hardingham TE. Cellular methods in cartilage research: primary human chondrocytes in culture and chondrogenesis in human bone marrow stem cells. Methods. 2008;45(1):2-9.

28. Strober W. Trypan blue exclusion test of cell viability. Curr Protoc Immunol. 2001; Appendix 3B. http://dx.doi.org/10.1002/0471142735.ima03bs21

29. Ekman L, Nilsson G, Persson L, Lumsdan JH. Volume of the synovia in certain joint cavities in the horse. Acta Vet Scand (Denmark). 1981;22:23-31.

30. Chomczynski P, Sacchi N. The single-step method of RNA isolation by acid guanidinium thiocyanate-phenol-chloroform extraction: twenty-something years on. Nature. 2006;1(2):581-5.

31. Livak KJ, Schmittgen TD. Analysis of relative gene expression data using realtime quantitative PCR and the 2- $\Delta \Delta C T$ method. Methods. 2001;25(4):402-8.

32. Peffers MJ, Milner PI, Tew SR, Clegg PD. Regulation of SOX9 in normal and osteoarthritic equine articular chondrocytes by hyperosmotic loading. Osteoarthr Cartil. 2010:18(11):1502-8.

33. Tew SR, Peffers MJ, McKay TR, Lowe ET, Khan WS, Hardingham TE, Clegg PD. Hyperosmolarity regulates SOX9 mRNA posttranscriptionally in human articular chondrocytes. Am J Physiol Cell Physiol. 2009;297(4):C898-906.

34. Peffers MJ, Liu X, Clegg PD. Transcriptomic signatures in cartilage ageing. Arthritis Res Ther. 2013;15(4):R98.

35. Richardson DW, Dodge GR. Effects of interleukin-1 $\beta$ and tumor necrosis factor-a on expression of matrix-related genes by cultured equine articular chondrocytes. Am J Vet Res. 2000;61(6):624-30.

36. Tung JT, Fenton Jl, Arnold C, et al. Recombinant equine interleukin-1ß induces putative mediators of articular cartilage degradation in equine chondrocytes. Can J Vet Res. 2002;66:19-25.

37. Ross TN, Kisiday JD, Hess T, Mcllwraith CW. Evaluation of the inflammatory response in experimentally induced synovitis in the horse: a comparison of recombinant equine interleukin 1 beta and lipopolysaccharide. Osteoarthr Cartil. 2012;20(12):1583-90.

38. Richardson DW, Dodge GR. Dose-dependent effects of corticosteroids on the expression of matrix-related genes in normal and cytokine-treated articular chondrocytes. Inflamm Res. 2003;52(1):39-49.

39. Busschers E, Holt JP, Richardson DW. Effects of glucocorticoids and interleukin-1 $\beta$ on expression and activity of aggrecanases in equine chondrocytes. Am J Vet Res. 2010;71(2):176-85.

40. Caron JP, Gandy JC, Schmidt M, et al. Influence of corticosteroids on interleukin-1 $\beta$-stimulated equine chondrocyte gene expression. Vet Surg. 2013:42(3):231-7.

41. Schaefer EC, Stewart AA, Durgam SS, et al. Effects of sodium hyaluronate and triamcinolone acetonide on glucosaminoglycan metabolism in equine articular chondrocytes treated with interleukin-1. Am J Vet Res. 2009;70(12):1494-501.

42. Yates AC, Stewart AA, Byron CR, et al. Effects of sodium hyaluronate and methylprednisolone acetate on proteoglycan metabolism in equine articular chondrocytes treated with interleukin-1. Am J Vet Res. 2006:67(12):1980-6.

43. Knych HK, Vidal MA, Chouicha N, et al. Cytokine, catabolic enzyme and structural matrix gene expression in synovial fluid following intraarticular administration of triamcinolone acetonide in exercised horses. Equine Vet J. 2017:49(1):107-15

44. Ng LJ, Wheatley S, Muscat GE, et al. SOX9 binds DNA, activates transcription, and coexpresses with type $\|$ collagen during chondrogenesis in the mouse. Dev Biol. 1997:183(1):108-21.

45. Bell DM, Leung KK, Wheatley SC, et al. SOX9 directly regulates the type 2 collagen gene. Nat Genet. 1997;16(2):174-8

46. Bi W, Deng JM, Zhang Z, Behringer RR, de Crombrugghe B. Sox9 is required for cartilage formation. Nat Genet. 1999:22(1):85-9.

47. Aigner T, Gebhard PM, Schmid E, et al. SOX9 expression does not correlate with type II collagen expression in adult articular chondrocytes. Matrix Biol. 2003:22(4):363-72

48. Basaria S, Wahlstrom JT, Dobs AS. Anabolic-androgenic steroid therapy in the treatment of chronic diseases. J Clin Endocrinol Metab. 2001:86(11): 5108-17. 